\title{
Design and Simulation for Brushless DC Motor Speed Control System Based on Fuzzy Control and Active Disturbance Rejection Control
}

\author{
Jian $\mathrm{HU}^{1, \text { a }}$, Ming $\mathrm{CHU}^{2, \mathrm{~b}}$ and Hanxu SUN ${ }^{3, \mathrm{c}}$ \\ 1,2,3 Automation School, Beijing University of Posts and Telecommunications, Beijing China \\ airienaa@163.com, bbuptchuming@163.com, chxsun@bupt.edu.cn
}

\begin{abstract}
Keywords: Brushless DC Motor, Fuzzy Control, Speed Control, Active Disturbance Rejection Control

Abstract. Brushless DC motor (BLDCM) is a nonlinear system of multi-variable, high-coupling and time-varying. Considering the high-precision speed control requirement of BLDCM, this paper designs a speed control system of BLDCM based on fuzzy controller And active disturbance rejection controller (ADRC). As the speed loop controller, a compound Fuzzy-ADRC controller is designed by setting the speed error threshold. The simulation results show that the system has good performance with response-rate, speed over regulated and the precision of regulation, and it produces better dynamic and static performance than traditional PID controller.
\end{abstract}

\section{Introduction}

Brushless DC motor (BLDCM) is a permanent magnet motor with the development of power electronic device, microelectronics and new permanent magnet materials. BLDCM has many advantages, such as high torque, low noise, simple structure, high efficiency, convenient maintenance, good dynamic performance, and is widely used in the fields of national defense, aerospace, medical devices, automotive electronics, robots and household appliances ${ }^{[1]}$. At present, most of the motors are controlled by the traditional PID controller. As the BLDCM speed control system is a nonlinear, multivariable and strong coupling system, some parameters of the BLDCM can be changed around the rated value, load changes will also bring disturbance, resulting in the difficulties of setting parameter, a set of rectified parameters can only have a better control effect in a small range, then resulting that the traditional PID control can't achieve the desired effect.

The fuzzy control is developed by the fuzzy mathematics which is proposed by the American cybernetics expert Zadeh. Fuzzy control does not depend on the controlled object mathematical model ${ }^{[2]}$, has strong adaptability to the nonlinearity of the controlled object, has strong robustness to the parameter variation of the controlled object, and has a wide application in the field of motor control. But the establishment of fuzzy rules and fuzzy membership function has no general rules, which mainly depends on experience. The simple fuzzy control is difficult to completely eliminate the steady-state error of the system, and the steady state accuracy is low.

Auto disturbance rejection controller (ADRC) is a new type of control theory, which is proposed by Professor Han Jing-Qing of Chinese Academy of Sciences ${ }^{[3 \sim 5]}$. The ADRC is developed from the nonlinear PID controller. The ADRC inherits the advantage of the PID controller which does not depend on the model of the control object, and overcome the inherent defects of classical PID based on the nonlinear structure. ADRC has the advantages of simple algorithm, strong anti-interference ability, small overshoot, fast convergence speed and high precision. ADRC can automatically detect and compensate the total disturbance of the system response by the internal and external disturbance, and can have very good control effect when the control object parameter is changed or under uncertain disturbance. ADRC has strong adaptability and robustness.

According to the characteristics of these two controllers, a BLDCM speed control system based on fuzzy control and ADRC is designed in this paper, and the control system is simulated by MATLAB/SIMULINK. The simulation results show that, compared with the traditional PID control, this control system has the characteristics of fast response, small overshoot, strong robustness and good dynamic performance. 


\section{Mathematical Model of BLDCM}

BLDCM is composed of the motor, the logic drive circuit and the rotor position sensor. The armature winding of the motor adopts the common star connection, and the rotor position sensor is installed on the rotating shaft to realize the detection of the motor position. According to the feedback information of the position sensor, the electronic commutation circuit controls the inverter turn on and off in a certain order.

The voltage balance equation of BLDCM is shown as Eq. 1,

$$
\left[\begin{array}{l}
u_{a} \\
u_{b} \\
u_{c}
\end{array}\right]=\left[\begin{array}{lll}
r & 0 & 0 \\
0 & r & 0 \\
0 & 0 & r
\end{array}\right]\left[\begin{array}{l}
i_{a} \\
i_{b} \\
i_{c}
\end{array}\right]+\left[\begin{array}{ccc}
L-M & 0 & 0 \\
0 & L-M & 0 \\
0 & 0 & L-M
\end{array}\right] \frac{d}{d t}\left[\begin{array}{l}
i_{a} \\
i_{b} \\
i_{c}
\end{array}\right]+\left[\begin{array}{c}
e_{a} \\
e_{b} \\
e_{c}
\end{array}\right],
$$

where $u_{a}, u_{b}, u_{c}$ are each phase voltage, $i_{a}, i_{b}, i_{c}$ are each phase current, $e_{a}, e_{b}, e_{c}$ are each phase opposite electromotive force, $r$ is each phase resistance. $L$ is each phase winding inductance, $M$ is each phase winding mutual inductance.

The electromagnetic torque equation and motion equation of the BLDCM are shown as Eq. 2,

$$
T_{e}=\frac{e_{a} i_{a}+e_{b} i_{b}+e_{c} i_{c}}{\omega}, J \frac{d \omega}{d t}=T_{e}-T_{L}-B \omega
$$

where $T_{e}$ is the electromagnetic torque, $T_{L}$ is the load torque, $B$ is the damping coefficient, $\omega$ is the motor angular speed and $J$ is the inertia.

\section{Design of BLDCM Speed Control System}

BLDCM speed control system is mainly composed of BLDCM, speed controller, current detection module, current controller, torque calculation module and inverter, as shown in Fig. 1. The current reference value $I_{i g}$ is calculated by the speed adjustment calculation of the speed input signal $V_{g}$ and the measured motor current speed $V_{s}$. The current feedback signal of the motor winding is converted into the current main circuit feedback current value $I_{i f}$. Use the current regulator output calculated by $I_{i g}$ and $I_{i g}$ to regulate the PWM signal, and then control the power switch tube'sturn on and off, allowing for the BLDCM speed control.

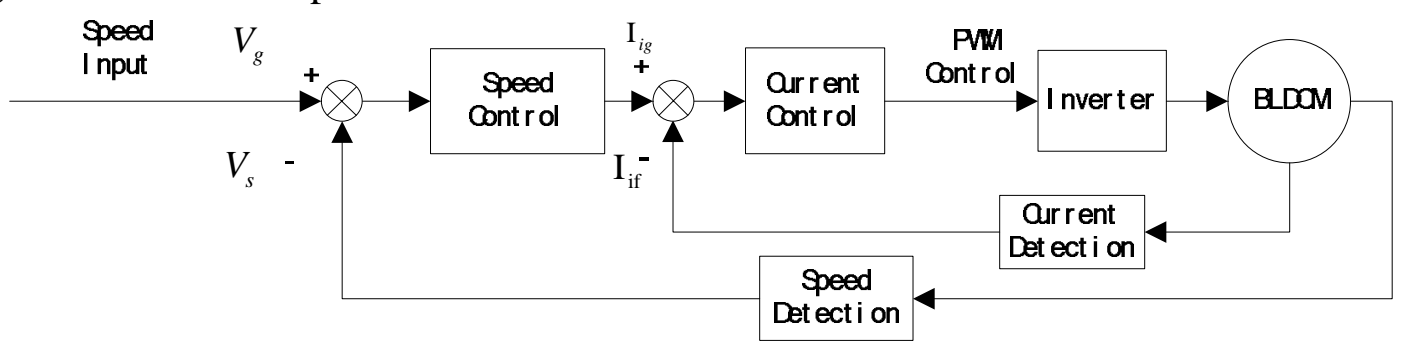

Fig. 1 Schematic Diagram of BLDCM Speed Control System

Design of Current Controller. The current loop is controlled by current hysteresis controller. Current hysteresis controllerregulates the current based on current hysteresiscontrol principle. The actual current changes follow the reference current, the controller changes the switching state of the inverterwhen the difference between the actual feedback current and the reference current is more than a certain value. The input of the current hysteresis controller is the actual current and the reference current, and the output is the control signal of the PWM inverter.

Design of Speed Controller. The speed loop is controlledby the compound fuzzy and active disturbance rejection controller, namely, the Fuzzy-ADRC controller. Set the speed error threshold $e_{0}$, When the speed error $e$ is greater than or equal to the threshold $e_{0}$, adopt the fuzzy controller. The 
ARDC is adopted when the speed error $e$ is less than the threshold $e_{0}$. In this way, the speed controller has the ARDC's and the fuzzy controller's advantages of high precision and quick response, so as to achieve the purpose of effectively improving system performance.

Design of Fuzzy Controller. The fuzzy controller adopts double input and single output structure. The two inputs of fuzzy controller are the system speed error and the speed error change ratio, the output of fuzzy controller is the reference current.

The quantitative universes of the system speed error, the speed error change ratio and the reference current are $[-6,6]$. The fuzzy subsets of the system speed error, the speed error change ratio and the reference current are $\{N B, N M, N S, Z O, P S, P M, P B\}$. The membership functions of the system speed error, the speed error change ratio and the reference current are Gaussian membership function.

Table 1 Fuzzy Control Rule Table

\begin{tabular}{|l|l|l|l|l|l|l|l|l|}
\hline \multicolumn{2}{|c|}{} & \multicolumn{7}{|c|}{ Error } \\
\cline { 3 - 10 } \multicolumn{2}{|c|}{} & PB & PM & PS & ZO & NS & NM & NB \\
\hline \multirow{4}{*}{$\begin{array}{l}\text { Error } \\
\text { Change }\end{array}$} & PB & NB & NB & NM & NM & NS & NS & PM \\
\cline { 2 - 9 } & PM & NB & NM & NS & NS & NS & ZO & PM \\
\cline { 2 - 9 } & PS & NB & NM & NS & NS & PS & PS & PB \\
\cline { 2 - 9 } & ZO & NB & NS & NS & ZO & PS & PS & PB \\
\cline { 2 - 9 } & NS & NB & NS & ZO & PS & PS & PM & PB \\
\cline { 2 - 10 } & NB & NM & ZO & PS & PS & PM & PM & PB \\
\cline { 2 - 9 } & & & & PM & PB & PB \\
\hline
\end{tabular}

The fuzzy reasoning method is Mandani fuzzy reasoning. When reasoning, the maximal and minimal operation is chosen as the synthesis operation based on the fuzzy implication, and then calculate the fuzzy output value. The output of fuzzy control is obtained by the defuzzification centroid method.

Design of ADRC. The ADRC is mainly composed of three parts, tracking differentiator (TD), extended state observer (ESO) and nonlinear state error feedback control law (NLSEF). The second order ADRC structure diagram is shown in Fig. 2. The function of TD is to arrange the transient process according to the system input, and to obtain the tracking and the differential signal of the system input. ESO is used to the system state and disturbance sum object according to the input and output of the controlled object. NLSEF calculates the control value based on the system error. The control value of the controlled object is obtained by compensating the system's disturbance to the control value calculated by NLSEF.

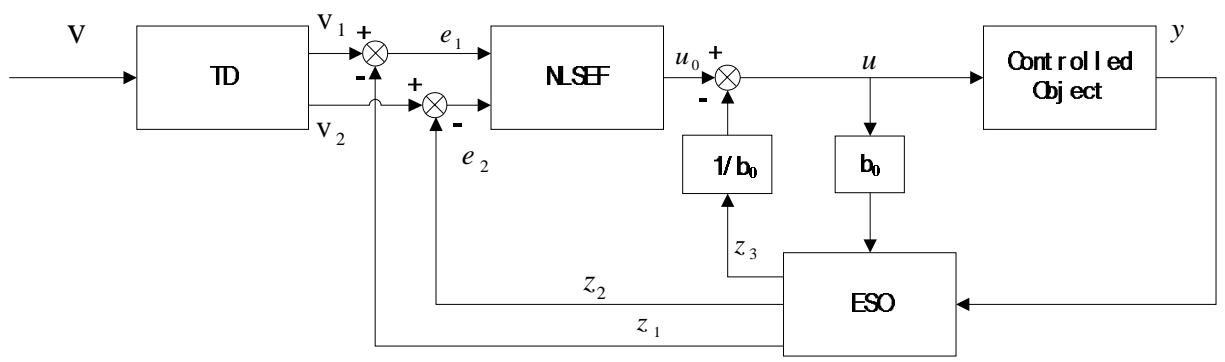

Fig. 2 The Second Order ADRC Structure Diagram

TD's equation is shown as Eq. 3,

$$
e=v_{1}-v_{0}, f h=f h a n\left(e, v_{2}, r_{0}, h\right), v_{1}=v_{1}+h \cdot v_{2}, v_{2}=v_{2}+h \cdot f h,
$$

function fhan $\left(e, v_{2}, r_{0}, h\right)$ is the most speed control function of TD, the equation is shown as Eq. 4 , 


$$
\begin{aligned}
& d=r_{0} h, d_{0}=r_{0} h^{2}, y=e+h v_{2}, a_{0}=\sqrt{d^{2}+8 r_{0}|y|} \\
& a=\left\{\begin{array}{c}
v_{2}+\frac{\left(a_{0}-d\right)}{2} \operatorname{sign}(y),|y|>d_{0} \\
v_{2}+\frac{y}{h},|y| \leq d_{0}
\end{array}, \text { fhan }=\left\{\begin{array}{c}
-r \cdot \operatorname{sign}(a),|a|>d . \\
-r \frac{a}{d},|a| \leq d
\end{array}\right.\right.
\end{aligned}
$$

ESO's equation is shown as Eq. 5,

$$
e=z_{1}-y, f e=f a l(e, 0.5, h), f e_{1}=f a l(e, 0.25, h), z_{1}=z_{2}-\beta_{01} e, z_{2}=z_{3}-\beta_{02} f e+b_{0} u, z_{3}=-\beta_{03} f e_{1} .
$$

NLSEF's equation is shown as Eq. 6 and Eq. 7,

$$
\begin{aligned}
& e_{1}=v_{1}-z_{1}, e_{2}=v_{2}-z_{2}, u_{0}=\beta_{1} \text { fal }\left(e_{1}, a_{1}, \delta\right)+\beta_{2} \text { fal }\left(e_{2}, a_{2}, \delta\right), u=u_{0}-z_{3} / b_{0}, \\
& f a l(\varepsilon, \alpha, \delta)=\left\{\begin{array}{c}
|\varepsilon|^{\alpha} \cdot \operatorname{sgn}(\varepsilon),|\varepsilon|>\delta \\
\frac{\varepsilon}{\delta^{1-\alpha}},|\varepsilon| \leq \delta
\end{array} .\right.
\end{aligned}
$$

In Eq. 4 Eq. 7, $v_{0}$ is the input signal, $v_{1}$ is the tracking signal, $v_{2}$ is the differential signal, $h$ is the integration step, $r_{0}$ is the speed factor, $z_{1}$ and $z_{2}$ are the state measurement of the controlled system, $z_{3}$ is the disturbance measurement of the controlled system, $b_{0}$ is the gain control input, $y$ is the speed feedback, $e_{1}$ and $e_{2}$ are the system errors, $u_{0}$ is he control value calculated by NLSEF, $u$ is the control value by compensation.

In the TD's equation, $r_{0}$ and $h$ are the adjustable parameters. In the ESO's equation, $\beta_{01}, \beta_{02}, \beta_{03}$, $b_{0}$ and $h$ are the adjustable parameters. In the NLSEF's equation, $\beta_{1}, \beta_{2}, \delta, a_{1}, a_{2}$ and $b_{0}$ are the adjustable parameters. By adjusting these parameters, the ADRC can achieve good control effect.

\section{Simulation Experiment and Analysis}

Based on the idea of modular modeling, the BLDCM Fuzzy-ADRCcontrol system simulation model is built by using MATLAB/Simulink. The Fuzzy-ADRCcontrol system includes the speed control module, the current hysteresis control module, the torque calculation module, the voltage inverter module, the motor module andthe commutation module. The Fuzzy-ADRCcontroller is applied to the speed control. The fuzzy controller is realized by the fuzzy inference system toolbox in MATLAB. The ADRC's three parts, TD, ESO and NLSEF, are designed and packaged by S-function.The Fuzzy-ADRC controller is achievedto switch the control strategy by using switch module in Simulink. The simulation model of Fuzzy-ADRC controller is shown in Fig. 3.

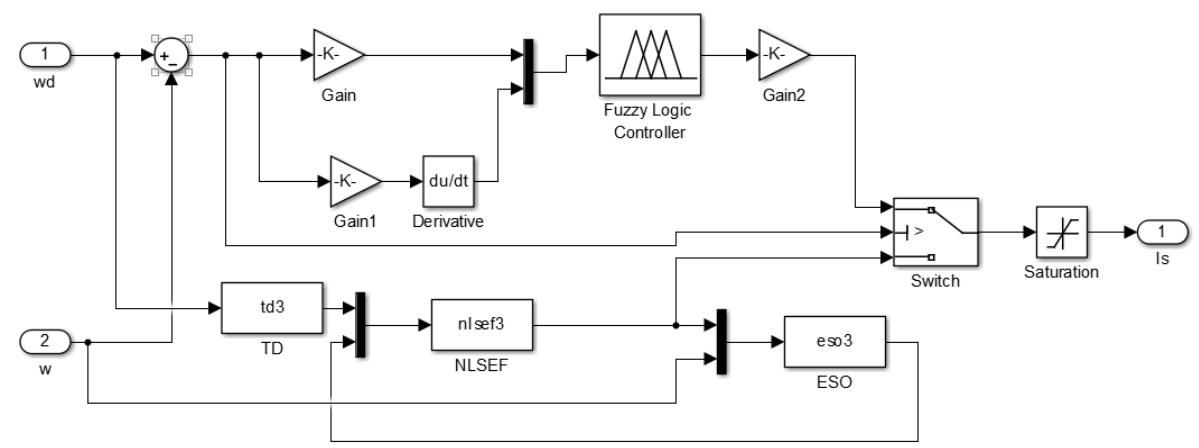

Fig. 3 Simulation Model of Fuzzy-ADRC Controller 
Select the motor parameters as, rated voltage $U_{N}=24 \mathrm{~V}$, rated speed $n_{N}=6700 \mathrm{r} / \mathrm{min}$, back-EMF coefficient $k_{e}=0.031 \mathrm{~V} /(\mathrm{rad} / \mathrm{s})$, phase resistance $R=1.31 \Omega$, phase inductance $L=1.64 \mathrm{H}$, rated load $T_{L}=0.0777 \mathrm{~N} \cdot \mathrm{m}$, rotary inertia $J=4.24 \times 10^{-6} \mathrm{~kg} \cdot \mathrm{m}^{2}$, damping coefficient $B=8.06 \times 10^{-6} \mathrm{~N} \cdot \mathrm{m} \cdot \mathrm{s} / \mathrm{rad}$. Select the ADRC parameters as, TD parameters include $r_{0}=15, h=0.02$, ESO parameters include $\beta_{01}=100$, $\beta_{02}=65, \beta_{03}=80, h=0.01, b_{0}=1$, NLSEF parameters include $\beta_{1}=100, \beta_{2}=10, \delta=0.01, a_{1}=0.75$, $a_{2}=1.25, b_{0}=1$.

The step response of the Fuzzy-ADRC controller and the PID controller is shown as Fig. 4. The sinusoidal signals response of the Fuzzy-ADRC controller and the PID controller is shown as Fig. 5. The square signals response of the Fuzzy-ADRC controller and the PID controller is shown as Fig. 6.

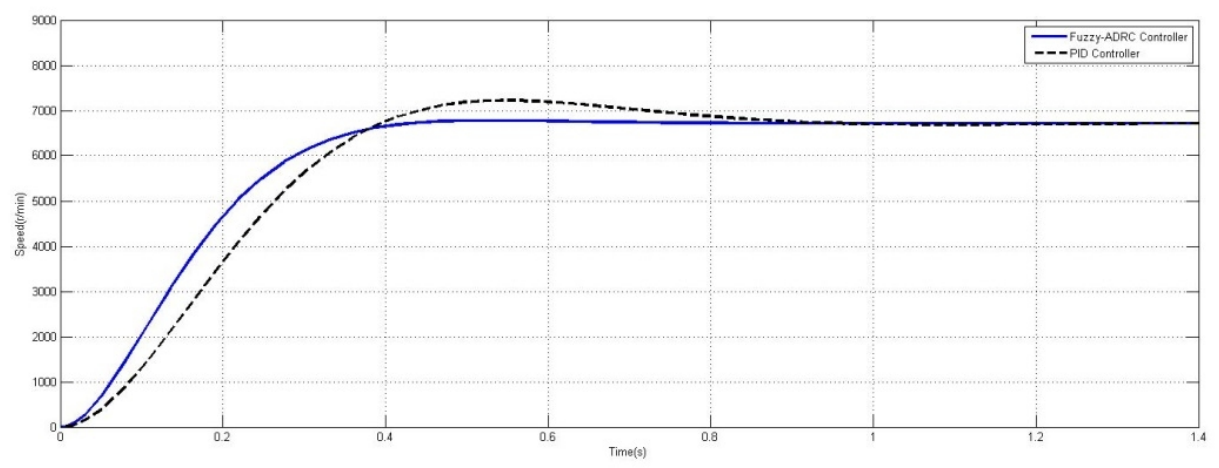

Fig. 4 The Step Response of the Fuzzy-ADRC Controller and the PID Controller

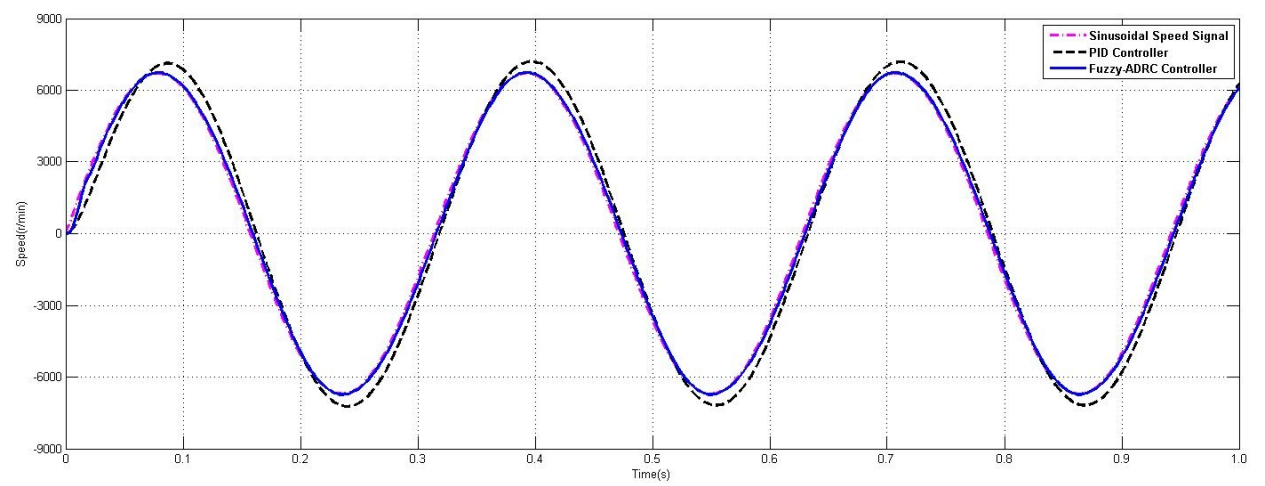

Fig. 5 The Sinusoidal Signals Response of the Fuzzy-ADRC Controller and the PID Controller

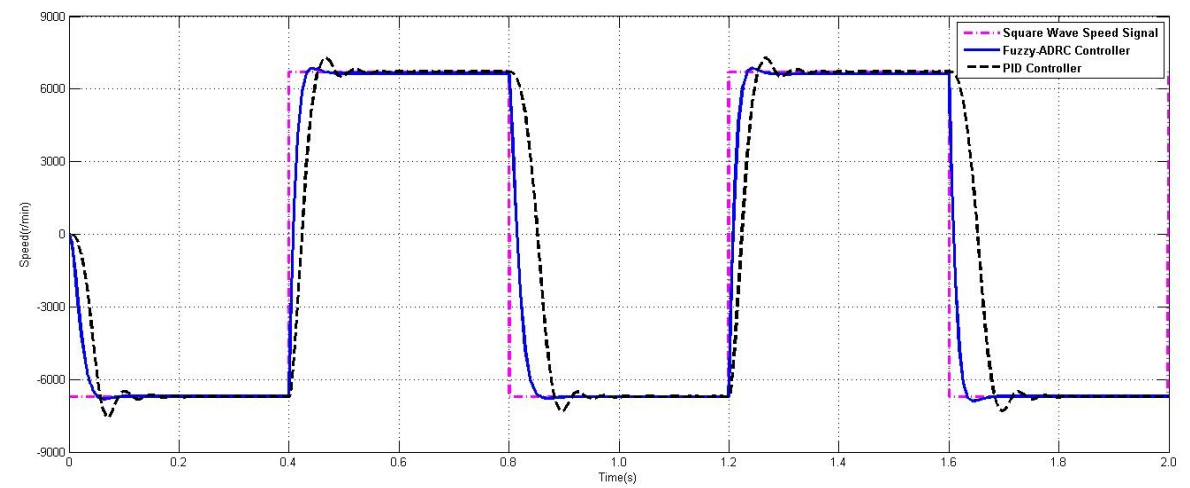

Fig. 6 The Square Signals Response of the Fuzzy-ADRC Controller and the PID Controller

From the step response curves of the Fuzzy-ADRC controller and the PID controller in Fig. 4, it can be seen that the overshoot of the traditional PID controller is larger, reaching $9.2 \%$, and the adjusting time is about $0.095 \mathrm{~s}$. However, the overshoot of the Fuzzy-ADRC controller is only $1.4 \%$, and the adjusting time is about $0.06 \mathrm{~s}$. From the sinusoidal signals response curves and the square signals response curves of the Fuzzy-ADRC controller and the PID controller in Fig. 5 and Fig. 6, it can be seen that the maximum tracking error of the traditional PID controller is $6.4 \%$ and $9.8 \%$ respectively. However, the Fuzzy-ADRC controller's maximum tracking error is only $0.7 \%$ and $1.8 \%$ respectively, and the tracking speed is obviously faster to the traditional PID controller. From simulation results, it 
can be seen that the Fuzzy-ADRC control system has good dynamic and static response ability, can commendablysuppress overshoot and shorten the adjusting time, and solvesthe contradiction between the overshoot and response speed ofthe traditional PID controller.

\section{Conclusions}

This paper designs a BLDCM Fuzzy-ADRC speed control system by combining the fuzzy control strategy and the ADRC strategy. The current loop is controlled by current hysteresis controller, and the speed loop is controlled by Fuzzy-ADRC controller. Fuzzy controller is adopted when the speed error is high and ADRC controller is adopted when the speed error is low. The control system is modeled and simulated by MATLAB/SIMULINK. The simulation results show that, the Fuzzy-ADRC control system has good dynamic and static response capability, the smaller overshoot, the faster adjusting speed, the higher adjustment precision. And the Fuzzy-ADRC controller has simply algorithm and sufficient feasibility.

\section{Acknowledgements}

This research was financially supported by the Project supported by the National Natural Science Foundation of China (51305039), the Fundamental Research Funds for the Central Universities (2014PTB-00-01) and the National Key Basic Research Program of China (973 Program 2013CB733000).

\section{References}

[1] Qing HUANG, Shoudao HUANG and Jiangchuang KUANG: Journal of Hunan University (Natural Sciences) 07(2012), p.37-43 (In Chinese).

[2] Zhicheng JI: Proceedings of the CSEE 25(5)(2005), p.104-109.

[3] Jingqing HAN: Control and Decision 13(1)(1998), p.19-23 (In Chinese).

[4] Jing GUO, Gang Yang: Modern Electronics Technique 10(2014), p.120-122.

[5] Changliang XIA, Wei YU: Proceedings of the CSEE 24(2006), p.137-142 (In Chinese).

[6] Yongguang MA, Ning RAN: Electronic Instrumentation Customers 04(2012), p.78-80.

[7] Chuanxiu WANG, Dongchao YAN: Computer Simulation 10(2015), p.430-434.

[8] Xiao-Bo ZHOU, Qunjing WANG: Electrical Machinery Technology 01(2010), p.8-10. 